OPEN ACCESS

Edited by:

Sudhakar Srivastava,

Banaras Hindu University, India

Reviewed by:

Bruno Gobin,

PCS Ornamental Plant Research,

Belgium

Menelaos Stavrinides,

Cyprus University of Technology,

Cyprus

${ }^{*}$ Correspondence:

George D. Broufas

gbroufas@agro.duth.gr

Specialty section:

This article was submitted to

Agroecology

a section of the journal

Frontiers in Ecology and Evolution

Received: 28 November 2018

Accepted: 27 March 2019

Published: 18 April 2019

Citation:

Samaras K, Pappas ML, Fytas E and Broufas GD (2019) Pollen Provisioning

Enhances the Performance of Amblydromalus limonicus on an Unsuitable Prey

Front. Ecol. Evol. 7:122. doi: 10.3389/fevo.2019.00122

\section{Pollen Provisioning Enhances the Performance of Amblydromalus limonicus on an Unsuitable Prey}

\author{
Konstantinos Samaras, Maria L. Pappas, Evangelos Fytas and George D. Broufas* \\ Laboratory of Agricultural Entomology and Zoology, Department of Agricultural Development, Democritus University of \\ Thrace, Orestiada, Greece
}

Amblydromalus limonicus is a polyphagous phytoseiid predator used for the biological control of thrips and whiteflies in greenhouse crops. Besides various prey species, $A$. limonicus can also feed on pollen of different plants. Cattail pollen has been previously shown to be suitable for the development and reproduction of $A$. limonicus. Hence, it could sustain its populations in periods of prey scarcity. In the present study, we hypothesized that pollen provisioning may benefit $A$. limonicus in mixed diets with prey of low quality, such as spider mites and thus, positively impact ecosystem services provided by this predator. For this, the performance and predation efficiency of $A$. limonicus against spider mites was assessed in the presence or absence of pollen. Our results show that pollen significantly shortens the developmental time and increases the survival and oviposition of the predator when mixed with spider mites, although it negatively affects its predation rate. Nevertheless, pollen enhances the maintenance of juvenile predators on the leaf by substantially decreasing their dispersal rate in the mixed diet with spider mites. In addition, the intrinsic rate of population increase $\left(r_{m}\right)$ of $A$. limonicus feeding with spider mites increased with the addition of pollen suggesting an increase in its population. Cattail pollen as supplementary food may thus expand the prey species range that $A$. limonicus could exploit. It can also enhance ecosystem services provided against other pests (thrips and whiteflies) by positively affecting the increase of $A$. limonicus population.

Keywords: phytoseiids, pollen, spider mites, mixed diet, predation, performance

\section{INTRODUCTION}

The success of biological control, an important ecosystem service provided by natural enemies is, in many circumstances, dependent on the availability, or exogenous application of alternative/supplementary foods. Plant-based foods such as nectar and pollen constitute important components of omnivorous diets of many polyphagous predators. They can function as supplemental foods in the presence of prey and as alternative foods when prey is scarce or not available in the crop (Coll and Guershon, 2002; Wäckers, 2005; Messelink et al., 2014). Thus, many omnivorous polyphagous predators rely heavily for population maintenance or build-up on the presence of plant food. These may be already available in the crop or, in the case of augmentative biological control, they are provided intentionally to enhance predator populations.

Among plant-feeding predatory arthropods, generalist predatory mites of the family Phytoseiidae include important biological control agents of key pests of crops of economic importance. Depending on the extent of their reliance of feeding on plant (pollen) and/or animal 
food, generalist phytoseiids are distinguished in different groups of feeding types [type III and IV according to McMurtry and Croft (1997); McMurtry et al. (2013)]. Among plant foods, the suitability of pollen of different plant species has been tested for their effects on the performance of several phytoseiids (e.g., Broufas and Koveos, 2001; Lorenzon et al., 2012; Goleva and Zebitz, 2013; Samaras et al., 2015). Due to the documented positive effects of many plant pollens, their use as supplementary or alternative foods is considered a promising method for the enhancement of biological control with the use of generalist phytoseiid species. In this context, pollen provisioning mainly aims at the early establishment and population build-up of phytoseiids as a "standing army" of natural enemies in the crop even before the arrival of the pest (Messelink et al., 2014; Pijnakker et al., 2016). Additionally, such tactic could enhance biological control achieved later on during the cropping season, because of the positive effects of the mixed diet (pollen plus prey) on the numerical response of the predators (van Rijn et al., 1999, 2002; Nomikou et al., 2002, 2010; Delisle et al., 2015b; Leman and Messelink, 2015). It can also maintain predator populations in the crop till the end of the cropping season even in the absence of prey and, thus, save growers from the additional costs required for the predator re-introduction. Other benefits of pollen provisioning include the ease of application and relatively limited problems related to its presence on the plants. To date, there is only one commercially available product of narrowleaved cattail (Typha angustifolia L.) pollen (Nurimite ${ }^{\mathrm{TM}}$, Biobest N.V.) used for enhancing phytoseiid populations in several crops (Messelink et al., 2014; Pijnakker et al., 2016).

Main problems related to pollen provisioning include the ability of certain pests to feed on pollen as well as negative effects on the predation rate of phytoseiid mites. For example, thrips (e.g., Frankliniella occidentalis or Thrips tabaci) which are key pests of several crops can also feed and reproduce on pollen of different plant species (Hulshof et al., 2003). Exogenous application of pollen to a crop with the aim to control thrips may backfire in the case the prey boosts its populations on the applied food. In addition, feeding on a mixed diet of prey and pollen may result in reduced prey consumption because of predator preference for the pollen over prey, or the frequent switching between the two components of the mixed diet (Nomikou et al., 2002, 2004, 2010; van Rijn et al., 2002). Nevertheless, both restrictions seem to be outweighed by the resulting substantial increase in the numerical response of certain predators, most possibly because of the nutritional benefits of mixed diets (Nomikou et al., 2010).

For a given species, the extent pest suppression can be enhanced by the provision of pollen may depend upon the nutritional quality of the components of a mixed diet (pollen and prey) and how this affects predator performance, besides initial predator-prey ratio (Leman and Messelink, 2015). Mixed diets consisting of two or more prey species or a mixture of pollen with prey have been shown to increase the numerical response of phytoseiid predators on prey of both high- (Nomikou et al., 2002, 2010; van Rijn et al., 2002) and low-quality (Messelink et al., 2010). Therefore, in theory, high quality pollen combined with low quality prey would positively affect biological control even in the event of decreased prey consumption per capita on the unsuitable prey (Pappas et al., 2013). On the other hand, variations in the quality of plant food (pollen) may differentially affect the numerical response of the predator on a specific prey (Samaras, 2018) and the same holds for the quality of prey.

Diet mixing is common among generalist predatory arthropods and benefits deriving from this behavior have been mainly attributed to the ability of several species to feed on prey containing different amounts of nutrients and thus actively restores nutritional imbalances in their diets (Mayntz et al., 2005). Studies on phytoseiid predatory mites have documented the positive effects of diet mixing on predator performance (e.g., Nomikou et al., 2002; van Rijn et al., 2002; Messelink et al., 2008; Pappas et al., 2013; Marques et al., 2015; Samaras et al., 2015). These can be roughly divided in two groups, the first assessing mixed diets consisting of different prey species and the second consisting of mixtures of prey with non-prey food. Our study is an addition to the second group differing, however, in that it deals with a prey species of low suitability for the predatory mite.

We hypothesized that the performance of A. limonicus, a generalist phytoseiid mite, could be enhanced in a mixed diet of pollen and prey. Amblydromalus limonicus is a natural enemy used for the biological control of thrips and whiteflies in greenhouse crops (van Houten et al., 2008; Hoogerbrugge et al., 2011; Knapp et al., 2013). Previous work has documented the high quality of cattail (T. latifolia and T. angustifolia L.) pollen as alternative food for this predator (Vangansbeke et al., 2014a,b; Samaras et al., 2015). In addition, mixed diets of prey of high quality (thrips larvae) with certain plant pollens have been shown to differentially affect $A$. limonicus population increase (Samaras, 2018). For this study, we assessed the performance of $A$. limonicus when feeding on a mixed diet consisting of cattail pollen (high quality supplementary food) with spider mites. Despite the ability of A. limonicus to feed on spider mites, certain species (e.g., Tetranychus urticae) produce dense webbing that dramatically hinders A. limonicus movement on and inside webs (van Houten et al., 2008). It would thus be important for A. limonicus to be able to consume spider mite individuals and increase its populations early enough before the rapid increase in spider mite populations and resulting webs. Moreover, in the absence of other prey, an alternative food of high quality such as cattail pollen could prove advantageous in a mixed diet with a prey of low quality, thus enabling A. limonicus to expand its prey range and also exploit spider mites, as was also shown in our previous work for the phytoseiid, Phytoseius finitimus (Pappas et al., 2013). We thus assessed the impact of pollen provisioning in a mixed diet with two-spotted spider mite T. urticae, a major agricultural pest (Hoy, 2011; Vacante, 2016) on the survival, development, dispersal, and reproduction of $A$. limonicus. In addition, we assessed prey consumption when $A$. limonicus fed on the mixed diet or spider mites alone.

\section{MATERIALS AND METHODS}

\section{Predator and Herbivore Rearing}

The laboratory rearing of the predatory mite Amblydromalus limonicus was established with adults of the commercially 
available product Limonica ${ }^{\circledR}$ (Koppert B.V. Berkel en Rodenrijs, The Netherlands). The predatory mites were reared on detached French bean leaves (Phaseolus vulgaris L.) that were placed with their upper surface on wet cotton wool in plastic cups at 26 $\pm 1{ }^{\circ} \mathrm{C}$ and 16:8 (L:D) h. Cattail pollen (T. latifolia L.) was provided on the leaves as food for the mites at $\sim 0.01 \mathrm{mg} / \mathrm{cm}^{2}$ (Samaras et al., 2015).

Spider mites ( $T$. urticae) originated from a population sampled from a tomato field in Alexandria (Northern Greece) and were reared on detached bean leaves on wet cotton wool inside plastic trays. The trays were kept in a climate room at $25 \pm$ $2{ }^{\circ} \mathrm{C}, 16: 8 \mathrm{LD}$ and $60-70 \% \mathrm{RH}$. Fresh bean leaves were provided every three days and the trays were filled with water to maintain leaf vigor.

\section{Pollen Diet}

Cattail (T. latifolia) pollen was collected from flowering plants in Northern Greece, as described in Broufas and Koveos (2000). Pollen was air dried for $12 \mathrm{~h}$, sieved ( $200 \mathrm{~mm}$ mesh) and stored at $-20^{\circ} \mathrm{C}$.

\section{Experimental Set-Up}

For the experiments, cucumber (Cucumis sativus L., cv Ginga F1, Geostore SA) plants were grown from seed in plastic pots $(\varnothing$ $12 \mathrm{~cm})$ in a climate room $\left(25 \pm 2^{\circ} \mathrm{C}, 16: 8 \mathrm{LD}, 60-70 \% \mathrm{RH}\right)$. The plants were watered every other day and fertilized once a week (N-P-K, 20-20-20). When plants were 4-5 weeks old, leaf discs $(3 \mathrm{~cm}$ in diameter) were punched out of cucumber leaves and placed with their upper surface individually on wet cotton wool in Petri dishes ( $5.5 \mathrm{~cm}$ in diameter).

Three treatments were included in our experiments: (1) spider mite-infested leaf discs (TUR), (2) pollen on spider mite-infested leaf discs (MIX), and (3) pollen on clean leaf discs (POL). To infest leaf discs with spider mites and create the desired web density simulating the onset of the development of spider mite population, five adult female spider mites were randomly chosen from the stock colony and transferred on each disc. To simulate a spider mite infestation at its early development we allowed spider mites to produce webs in the half of the leaf surface of our experimental arenas. For this purpose, half the surface of each leaf disc was covered with wet filter paper to prevent mites laying eggs and spinning web in that area. This also enabled predatory mites to easily move on the leaf discs and consume prey in all experimental treatments.

After $24 \mathrm{~h}$ the filter paper and the mites were removed. The leaf discs were subsequently placed individually to float on water in the cells of multi-well tissue culture plates (Corning ${ }^{\circledR}$ ), each consisting of six cells $(3.52 \mathrm{~cm}$ in diameter). Daily, fresh spider mite larvae $(n=12)$ were offered to each predator on the web-covered half part of the leaf disc after recording the developmental stage, juvenile survival, female oviposition and survival, depending on the experiment (juvenile or adult performance) as well as adult prey consumption i.e., number of dead individuals. For the POL treatment, pollen was placed on the respective half of the leaf disc that was not covered with filter paper during its preparation. Plates of all treatments were maintained in climate boxes at $26 \pm 1^{\circ} \mathrm{C}$ and 16:8 (L:D) h. After hatching, the number of spider mite larvae was set to twelve per leaf disc.

\section{Juvenile Development, Survival, and Dispersal}

To assess the effect of pollen provisioning on the development and survival of $A$. limonicus when fed with spider mites, young adult females (3-4 days old) from the stock colony were transferred on bean leaves in plastic cups and allowed to lay eggs for $24 \mathrm{~h}$. Newly hatched larvae of A. limonicus were placed individually on the center of the experimental leaf discs prepared as described above. Developmental stage, survival, and dispersal (predators trapped in the wet cotton barrier surrounding the leaf discs were considered as dispersing individuals) were recorded twice daily until mites reached adulthood. For each treatment 48 individuals (predatory mites, each mite on one leaf disc) were used. The effect of diet (treatment) on total developmental time was evaluated with one-way analysis of variance (ANOVA) and means were further compared with Tukey's HSD test $(P<0.05)$. Normality and homoscedasticity were checked by Kolmogorov-Smirnov and Levene's test, respectively, (SPSS, 2011). The percentages of adult emergence (juvenile survival) and cumulative dispersal rate during juvenile development among the different treatments were compared by $\chi^{2}$ test.

\section{Adult Survival, Egg Production, and Prey Consumption}

To assess the effects of pollen provisioning on the performance of $A$. limonicus adults when fed with spider mites, newly molted adults were sexed and placed in pairs (one female plus one male) for 1 day for mating to occur on experimental leaf discs prepared as described above. Afterwards, the male was removed and oviposition, survival, and prey consumption of each female was recorded for the first 2 weeks of each female's life, which is the time period with the highest expected reproduction output. For each treatment, 25 replicates (adult females, each mite on one leaf disc) were used. Data for days 2-10 were only included in the analyses; day 1 data were excluded because of the presence of both males and females on the leaf discs. In addition, data for days 11-14 were excluded because of the low number of surviving individuals in the spider mite diet. To calculate progeny sex ratio, for each treatment, all eggs were collected and transferred to fresh leaf discs as above. Juveniles fed with the same type of food (spider mite larvae, spider mite larvae plus pollen, pollen) as their parents till adult emergence. A generalized linear model with a Poisson error distribution and log link function with time and diet and their interaction as factors was used to evaluate the effects on the mean daily oviposition and prey consumption rates of adult females. In case of significant differences, marginal means were further separated by pairwise comparisons between the levels of the main factor (diet) by Bonferroni test $(P<0.05)$ (SPSS, 2011).

\section{Intrinsic Rates of Population Increase $\left(r_{m}\right)$}

Calculations of the intrinsic rates of increase $\left(r_{m}\right)$ of $A$. limonicus at the different treatments were performed by solving the equation: $r_{m}=$ (net reproductive rate) $\mathrm{x} \exp \left[\left(-\mathrm{r}_{\mathrm{m}}\right) \mathrm{x}\right.$ (egg-to-egg 
period)] (Sabelis and Janssen, 1994), where net reproductive rate $=$ (peak oviposition rate) $\mathrm{x}$ (survival in egg-to-egg period) $\mathrm{x}$ (sex ratio) as described in Nomikou et al. (2001).

\section{RESULTS}

\section{Effects of Pollen Provisioning in Mixed Diet With Spider Mites on A. limonicus Juvenile Development, Survival, and Dispersal}

Juvenile survival was significantly affected by treatment (diet) (Figure 1A; $\chi^{2}=47.19$, df $=2, P<0.001$ ). Spider mites alone resulted in significantly lower survival percentage compared to pollen alone (Figure 1A). However, mixing spider mites with pollen significantly increased juvenile survival to levels comparable to pollen alone (Figure 1A). Thus, providing pollen to a diet consisting of spider mites helps in adverting the negative impact of the low quality prey on A. limonicus survival.

We further counted the number of live mites found on the leaf discs to assess the rate of predator dispersal in the different treatments (diets). We found a significant effect of diet on the number of dispersing predators (Figure 1B; $\chi^{2}=37.50, \mathrm{df}=2$, $P<0.001)$. The highest dispersal was recorded when juveniles fed on spider mites (Figure 1B) which, however, decreased with the addition of pollen in a mixed diet with spider mites (Figure 1B).

Similarly, juvenile developmental time was significantly affected by diet (Figure 1C; $F=60.17$, df $=2,89, P<0.001$ ). Mean developmental time was significantly shorter on pollen compared to spider mites (Figure 1C). The addition of pollen in a mixed diet with spider mites resulted in a significant decrease in the time needed for A. limonicus juveniles to complete development (Figure 1C).

\section{Effects of Pollen Provisioning in Mixed Diet With Spider Mites on A. limonicus Adult Performance and Predation Efficiency}

Adult survival was significantly affected by diet (Figure 2, $\chi^{2}=9.15$, df $\left.=2, P=0.010\right)$. Feeding on spider mites resulted in a rapid decline in the survival of $A$. limonicus females compared to those feeding on pollen or a mixture of pollen with spider mites (Figure 2). No significant difference was recorded in the survival of $A$. limonicus females when these fed on pollen or mixed diet (Figure 2).

The numbers of eggs laid by $A$. limonicus from day 2 till day 10 of their adult life were significantly different among diets (Figure 3A, $\chi^{2}=69.58$, df $=2$, $P<0.001$ ) and with time (Figure 3A, $\chi^{2}=20.55$, df $=8, P<0.05)$. On average, females laid a significantly higher number of eggs when feeding on pollen (1.6 \pm 0.09 eggs/female/day) compared to those feeding on a mixed diet $(1.3 \pm 0.08$ eggs/female/day $)$ or spider mites (0.009 \pm 0.002 eggs/female/day) (Figure 3A). However, the females feeding on the mixed diet laid significantly more eggs compared to those feeding on spider mites alone (Figure 3A). The interaction between
A

B
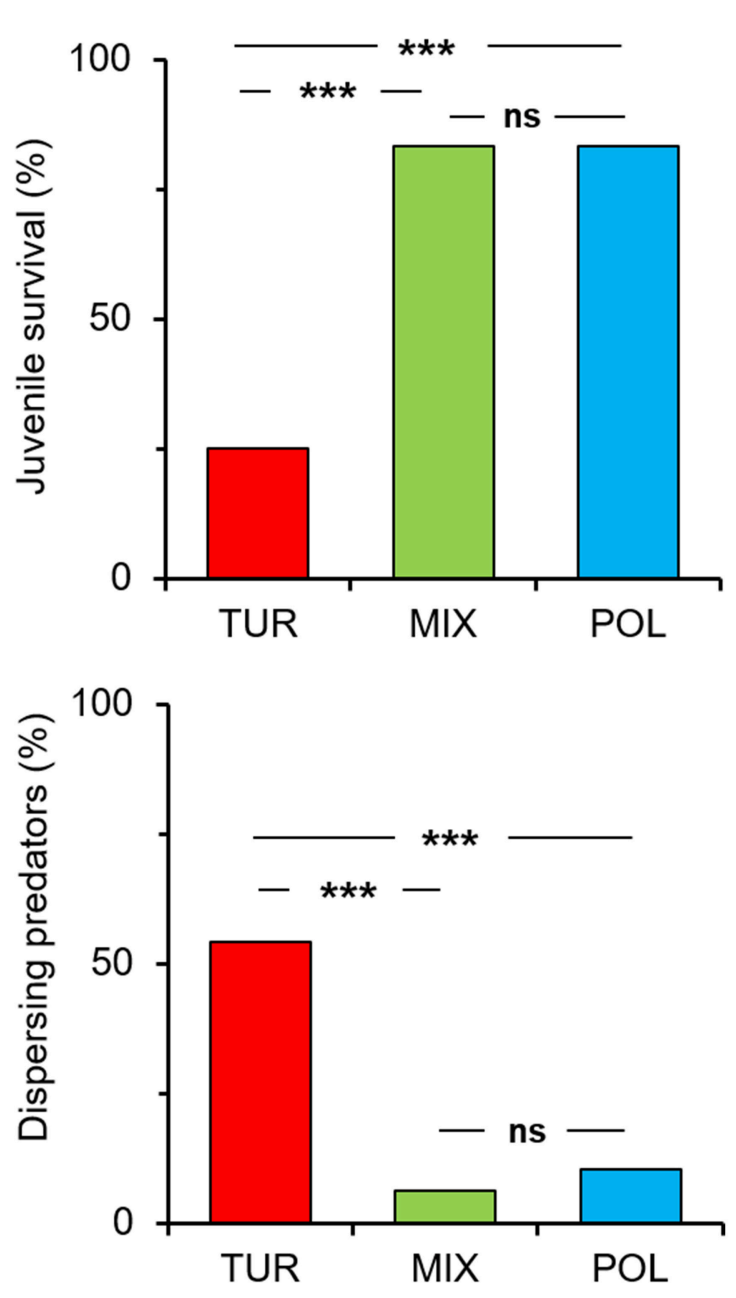
12

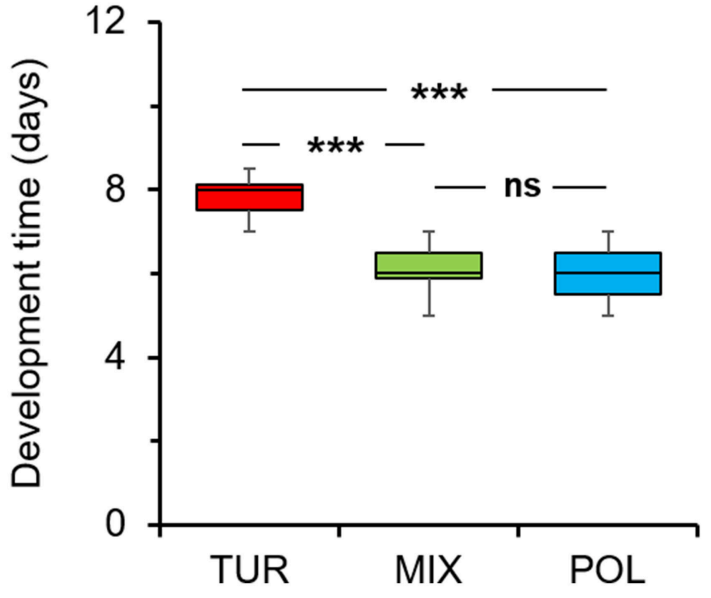

FIGURE 1 | Effects of pollen provisioning in a mixed diet with spider mites on the development and dispersal of Amblydromalus limonicus juveniles. Eggs laid by predator females within $24 \mathrm{~h}$ were individually transferred on leaf discs where juveniles ( $n=48$ per treatment) had access to either Typha latifolia pollen (blue bar, POL), spider mite larvae (red bar, TUR), or a mixed diet consisting of spider mite larvae plus pollen (green bar, MIX) throughout their development to adults. (A) Percentage of juvenile survival at reaching

(Continued) 
FIGURE 1 | adulthood, (B) percentage of dispersing mites per leaf disc, and (C) developmental time in the different diets (each box plot horizontal line shows the median, upper and lower box boundaries the quartiles, and whiskers the extreme values within a category). Significant differences between treatments are indicated by asterisks; A-B: $\chi^{2}$-test; (C) Tukey-HSD test: $\left.P<0.001{ }^{\star \star \star}\right)$, ns, not significant.

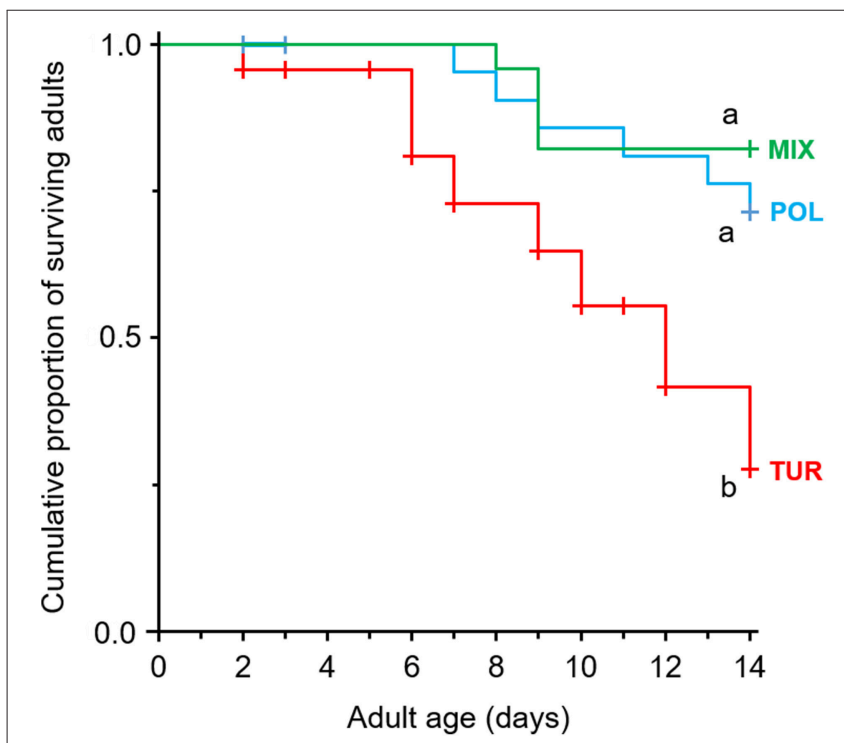

FIGURE 2 | Effects of pollen provisioning in a mixed diet with spider mites on the survival of adult Amblydromalus limonicus. Female adults were feeding on either Typha latifolia pollen (blue line, POL), spider mite larvae (red line, TUR), or a mixed diet consisting of spider mite larvae plus pollen (green line, MIX) for a period of 2 weeks. Shown are Kaplan-Meier survival curves of adults $(n=25$ per treatment) feeding on the different diets. Significant differences between treatments are indicated by different letters by Mantel-Cox log-rank tests $(P<0.05)$. Censored observations (dispersing predators) are shown as crosses on the lines.

diet and time was not significant $\left(\chi^{2}=3.98, \mathrm{df}=15\right.$, $P=0.998)$.

The consumption of prey (spider mites) by $A$. limonicus females was significantly affected by diet (Figure 3B, $\chi^{2}=53.35$, $\mathrm{df}=1, P<0.001$ ) and not with time (Figure 3B, $\chi^{2}=11.27$, $\mathrm{df}=8, P=0.187)$. More spider mites were consumed when A. limonicus females had access to spider mites only $(2.2 \pm$ $0.13)$ than when they were also provided with pollen (1.1 \pm 0.08 ) (Figure 3B). The interaction between diet and time was not significant $\left(\chi^{2}=8.43, \mathrm{df}=8, P=0.392\right)$.

\section{Effects of Pollen Provisioning in Mixed Diet With Spider Mites on Intrinsic Rates of Increase $\left(r_{m}\right)$ of $A$. limonicus}

The population increase of $A$. limonicus was assessed by calculating intrinsic growth rates $\left(r_{m}\right)$ values on the different diets. The highest $r_{m}$ value (0.219) was recorded when predators fed on pollen, and the lowest $(0.040)$ on the spider mite diet. Remarkably, this value increased to 0.190 when mixing spider
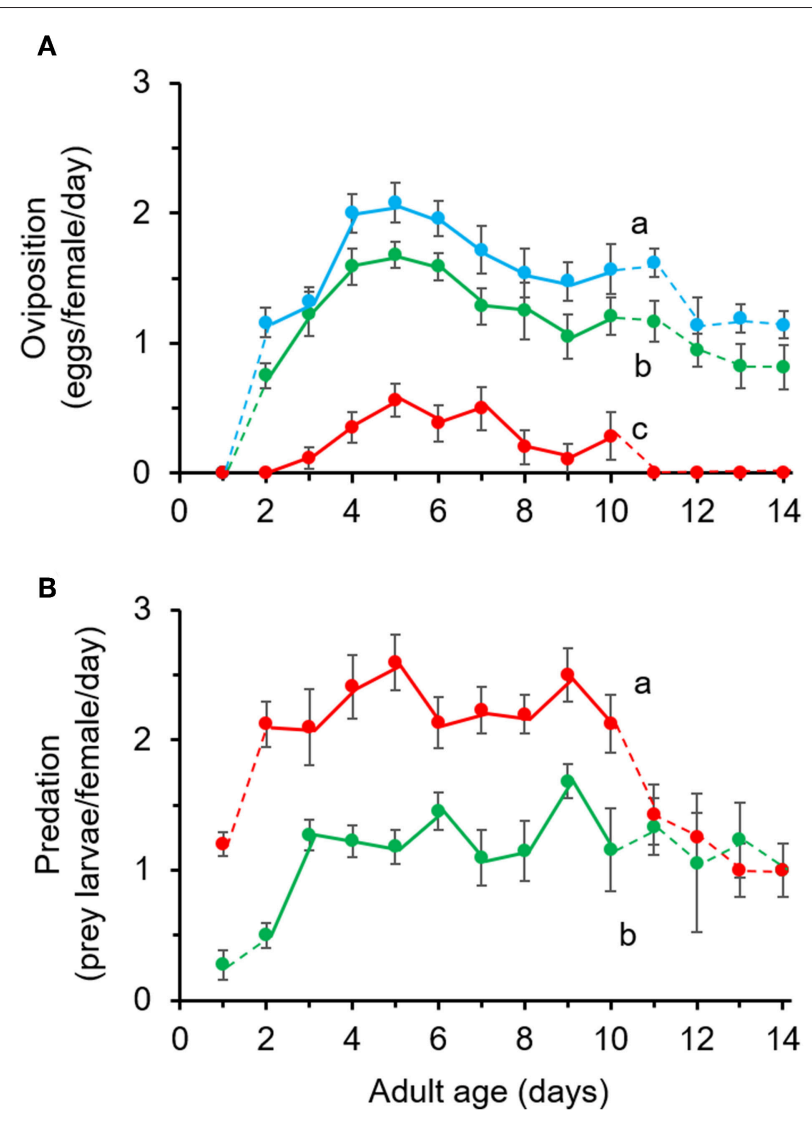

FIGURE 3 | Effects of pollen provisioning in a mixed diet with spider mites on the performance of adult Amblydromalus limonicus. Female adults $(n=25$ per treatment) were feeding on either Typha latifolia pollen (blue line, POL), spider mite larvae (red line, TUR), or a mixed diet consisting of spider mite larvae plus pollen (green line, MIX) for a period of 2 weeks. Shown are the mean $( \pm \mathrm{SE})$

(A) number of eggs per female per day and (B) number of consumed prey (spider mite larvae) per female per day of young female $A$. limonicus from day 2 to day 10 of their adult life. Only data shown in full lines (day 2-10) were included in statistical analyses. Per panel, lines with different letters are significantly different (GLM followed by Bonferroni test, $P<0.001$ ).

mites with pollen suggesting a higher population increase for $A$. limonicus on the mixed diet.

\section{DISCUSSION}

Generalist phytoseiid predators are capable of exploiting both animal and plant food (McMurtry and Croft, 1997; McMurtry et al., 2013) but to which extent plant food (e.g., pollen) provisioning could affect the performance of phytoseiids that also have access to prey has been scarcely addressed so far (e.g., Nomikou et al., 2002; van Rijn et al., 2002; Messelink et al., 2010; Pappas et al., 2013). Moreover, our limited knowledge on mixed diet effects on phytoseiid performance is restricted to the preferred prey of each particular predator species, and only barely studied in combination with prey species of lower suitability [e.g., spider mites for P. finitimus in Pappas et al., 2013]. Our data shows that cattail pollen provisioning could enable A. limonicus 
to better exploit spider mites, a prey of lower quality than its main prey (thrips or whiteflies) via its positive effects on the population increase $\left(r_{m}\right)$ of the predator when feeding on the mixed diet of pollen and spider mites.

The positive impact of pollen provisioning on juveniles and adult life-history traits recorded in our study is in agreement with previous studies with phytoseiids in which the predator performs better on a mixed diet than on the single prey component of the mixed diet. Herein however, the positive effects on A. limonicus oviposition were still stronger when feeding on pollen than on the mixed diet. Our study shows the ability of A. limonicus to overcome the nutritional limitations imposed by $T$. urticae by also feeding on pollen and does not fall in the group of studies confirming synergistic effects of mixed diet components on predator performance (e.g., Marques et al., 2015).

All life-history traits studied herein did not differ among the pollen and mixed diet treatments with the exception of female egg production which was significantly higher in the pollen diet, suggesting that no synergistic effects were recorded in our study for any of the indexes studied. As we only recorded prey consumption by the adult females, we cannot exclude the possibility that juvenile predators avoided spider mites and mainly relied their feeding on pollen alone during development, although dead spider mite individuals were regularly observed on the experimental leaf discs. On the other hand, adult females were shown to actively prey on spider mite larvae and despite prey consumption being lower in the mixed diet, it did not negatively impact adult survival but the resulting egg production by A. limonicus females. Overall, it seems like the overall positive effects of pollen provisioning on A. limonicus population increase should be mainly attributed to the enhancement of juvenile development and survival and, to a lesser extent, to increased egg production in the mixed compared to the single prey diet.

Decreased prey consumption can be an important side-effect of prey mixing with pollen that negatively impacts predation efficiency of generalist phytoseiids (van Baalen et al., 2001; Skirvin et al., 2007; Pappas et al., 2013; Leman and Messelink, 2015; Vangansbeke et al., 2016). It may be related to the predator shift exclusively toward pollen grains, which are easier to consume, requiring no energy to forage compared to prey individuals. Moreover, predator shift might also relate to the active foraging of the predator toward a more nutritious food over lower quality prey. Whereas, higher nutritional quality might only explain predator choice of pollen over low quality prey, predator shift to mainly pollen feeding might apply to both low and high quality prey species. On the other hand, active, or random consumption of variable quantities of both pollen and prey by the predator, can result to its satiation and thus, reduced prey consumption compared to predators having access to prey only. In this study, pollen provisioning to $A$. limonicus in a mixed diet with spider mites resulted in reduced spider mite consumption (Figure 3B). Similarly, other studies have highlighted the role of pollen in reducing prey consumption. For example, thrips consumption by the phytoseiids Amblyseius swirskii or Neoseiulus cucumeris decreased by $\sim 50 \%$ when predators were feeding on a mixed diet of pollen and thrips (Skirvin et al., 2007; Delisle et al., 2015a; Leman and Messelink, 2015). We herein recorded a similar percentage $(52.7 \%)$ in the reduction of prey consumption by A. limonicus in the mixed diet compared to spider mites only. Whether this reduction is related to predator satiation or a shift toward pollen cannot be easily inferred from the results of the present study.

Overall effects of pollen provisioning on A. limonicus performance derived from the stronger population increase in the mixed diet compared to the diet including only prey. Such an increase suggests that, in the absence of more suitable prey, the population of the predator will still be increasing on the mixed diet but at higher rates than when fed on the low quality prey (spider mites) alone. In the long-term, pollen should increase predator/prey ratios and thus eliminate the low quality effects of the juvenile and adult food (Nomikou et al., 2004). Moreover, our results on A. limonicus dispersal in the different diets suggest that pollen provisioning also corroborates the maintenance of juvenile predators in the release area thus, contributing to the population increase of the predator. Similarly, diet mixing of different prey species but no plant food, can result in increased numerical response of the shared predator negatively affecting one or all of the involved prey (also termed "apparent competition") (Holt, 1977; Chaneton and Bonsall, 2000). On the other hand, "apparent mutualism" relates to the satiation of the predator and the subsequent reduction in the consumption of both prey species (Holt, 1977; Holt and Kotler, 1987). Both types of predator-mediated interactions among prey species have been recorded for phytoseiids and, time, seems to be an important determinant of the expression of either type of interaction, with apparent mutualism realized in the short-term whereas apparent competition in the long-term for the predator-prey interaction (Messelink et al., 2008, 2010; van Maanen et al., 2012; MuñozCárdenas et al., 2017). In the present study, we used a mixed diet of spider mites (prey) and pollen (plant food) but the results seem to follow the general trend previously described for mixed diets consisting of prey only. Similar trends in the effects of pollen provisioning as supplementary food on phytoseiid population increase have also been demonstrated in studies (e.g., Nomikou et al., 2002, 2010; van Rijn et al., 2002; Messelink et al., 2010; Pappas et al., 2013) highlighting the importance of pollen in biological pest control.

To conclude, pollen provisioning is shown herein to enable $A$. limonicus population increase in the presence of low quality prey such as spider mites. It is thus expected that, in the long term, this initial build-up of predator population on low quality prey would enable A. limonicus to efficiently confront other prey species (e.g., thrips or whiteflies) arriving later in the crop. However, there are a number of restrictions that apply in the extrapolation of our results to real conditions that need to be discussed and further evaluated in future studies. Our experimental set-up was based on the assumption that the predator would have to control a spider mite population at its early development. In this situation, spider mites would produce low webbing and thus, A. limonicus would easily move and forage on the leaf surface. This is also particularly important for the juvenile predators, that would consume pollen grains more easily on a relatively 
free- than on a full-web leaf. Moreover, our set-up included only one prey species which may not be the case in certain time periods during the cropping season. Finally, as we only recorded juvenile development and adult egg production for a limited time period, future studies should include greenhouse experiments to confirm the hypothesis that A. limonicus would control spider mites in the long-term via increased population increase. From an applied perspective, A. limonicus is an important biological control agent currently used for thrips and whitefly control (van Houten et al., 2008; Hoogerbrugge et al., 2011; Knapp et al., 2013). Previous studies have demonstrated the suitability of several pollens for this predator (Vangansbeke et al., 2014b; Samaras et al., 2015) and pollen provisioning is expected to enhance its ability to control thrips (Samaras, 2018). The results of the present study add on the current literature on the effects of pollen provisioning on the numerical response of phytoseiid predatory mites but also reveal the role of cattail pollen in enhancing the ability of $A$. limonicus to also exploit a prey of low quality and thus, to possibly expand its biological control use to spider mites.

\section{REFERENCES}

Broufas, G. D., and Koveos, D. S. (2000). Effect of different pollens on development, survivorship and reproduction of Euseius finlandicus (Acari: Phytoseiidae). Environ. Entomol. 29, 743-749. doi: 10.1603/0046-22 5X-29.4.743

Broufas, G. D., and Koveos, D. S. (2001). Cold hardiness characteristics in a strain of the predatory mite Euseius (Amblyseius) finlandicus (Acari: Phytoseiidae) from Northern Greece. Ann. Entomol. Soc. Am. 94, 82-90. doi: 10.1603/00138746(2001)094[0082:CHCIAS]2.0.CO;2

Chaneton, E. J., and Bonsall, M. B. (2000). Enemy-mediated apparent competition: empirical patterns and the evidence. Oikos 88, 380-394. doi: $10.1034 /$ j.1600-0706.2000.880217.x

Coll, M., and Guershon, M. (2002). Omnivory in terrestrial arthropods: mixing plant and prey diets. Annu. Rev. Entomol. 47, 267-297. doi: 10.1146/annurev.ento.47.091201.145209

Delisle, J. F., Brodeur, J., and Shipp, L. (2015a). Evaluation of various types of supplemental food for two species of predatory mites, Amblyseius swirskii and Neoseiulus cucumeris (Acari: Phytoseiidae). Exp. Appl. Acarol. 65, 483-494. doi: 10.1007/s10493-014-9862-3

Delisle, J. F., Shipp, L., and Brodeur, J. (2015b). Apple pollen as a supplemental food source for the control of western flower thrips by two predatory mites, Amblyseius swirskii and Neoseiulus cucumeris (Acari: Phytoseiidae), on potted chrysanthemum. Exp. Appl. Acarol. 65, 495-509. doi: 10.1007/s10493-014-9863-2

Goleva, I., and Zebitz, C. P. (2013). Suitability of different pollen as alternative food for the predatory mite Amblyseius swirskii (Acari, Phytoseiidae). Exp. Appl. Acarol. 61, 259-283. doi: 10.1007/s10493-0139700-z

Holt, R. D. (1977). Predation, apparent competition, and the structure of prey communities. Theor. Popul. Biol. 12, 197-229. doi: 10.1016/0040-5809(77)90042-9

Holt, R. D., and Kotler, B. P. (1987). Short-term apparent competition. Am. Natural. 130, 412-430. doi: 10.1086/284718

Hoogerbrugge, H., van Houten, Y., Knapp, M., and Bolckmans, K. (2011). Biological control of thrips and whitefly on strawberries with Amblydromalus limonicus and Amblyseius swirskii. IOBC/Wprs Bull. 68, 65-69. Available online at: https://www.iobc-wprs.org/members/shop_en. cfm?mod_Shop_detail_produkte $=43$

Hoy, M. A. (2011). Agricultural Acarology: Introduction to Integrated Mite Management. Boca Raton: CRC Press.

\section{AUTHOR CONTRIBUTIONS}

GB and MP conceived and designed the experiments. KS and EF performed the experiments. GB analyzed the data. MP, KS, and GB wrote the manuscript. All authors read, edited and approved the final manuscript.

\section{FUNDING}

Part of this work was supported by the Postgraduate Programmes 60065 \& 80227 of the Department of Agricultural Development, Democritus University of Thrace. MP and KS received funding from the Onassis Foundation (grant numbers R-ZJ 003 to MP and G-ZJ 052 to $\mathrm{KS}$ ).

\section{ACKNOWLEDGMENTS}

We would like to thank the undergraduate students Vassiliki Mantali, Anneta Triantafyllou, and Georgia Tavlaki for technical help during the course of the experiments.

Hulshof, J., Ketoja, E., and Vänninen, I. (2003). Life history characteristics of Frankliniella occidentalis on cucumber leaves with and without supplemental food. Entomol. Exp. Appl. 108, 19-32. doi: 10.1046/j.1570-7458.2003.00061.x

Knapp, M., van Houten, Y., Hoogerbrugge, H., and Bolckmans, K. (2013). Amblydromalus limonicus (Acari: Phytoseiidae) as a biocontrol agent: literature review and new findings. Acarologia 53, 191-202. doi: 10.1051/acarologia/20132088

Leman, A., and Messelink, G. J. (2015). Supplemental food that supports both predator and pest: a risk for biological control? Exp. Appl. Acarol. 65, 511-524. doi: 10.1007/s10493-014-9859-y

Lorenzon, M., Pozzebon, A., and Duso, C. (2012). Effects of potential food sources on biological and demographic parameters of the predatory mites Kampimodromus aberrans, Typhlodromus pyri and Amblyseius andersoni. Exp. Appl. Acarol. 58, 259-278. doi: 10.1007/s10493-012-9580-7

Marques, R. V., Sarmento, R. A., Lemos, F., Pedro-Neto, M., Sabelis, M. W., Venzon, M., et al. (2015). Active prey mixing as an explanation for polyphagy in predatory arthropods: synergistic dietary effects on egg production despite a behavioural cost. Funct. Ecol. 29, 1317-1324. doi: 10.1111/1365-2 435.12439

Mayntz, D., Raubenheimer, D., Salomon, M., Toft, S., and Simpson, S. J. (2005). Nutrient-specific foraging in invertebrate predators. Science 307, 111-113. doi: 10.1126/science.1105493

McMurtry, J. A., and Croft, B. A. (1997). Life-styles of phytoseiid mites and their roles in biological control. Annu. Rev. Entomol. 42, 291-321. doi: 10.1146/annurev.ento.42.1.291

McMurtry, J. A., De Moraes, G. J., and Sourassou, N. F. (2013). Revision of the lifestyles of phytoseiid mites (Acari: Phytoseiidae) and implications for biological control strategies. Syst. Appl. Acarol. 18, 297-320. doi: 10.11158/saa.18.4.1

Messelink, G. J., Bennison, J., Alomar, O., Ingegno, B. L., Tavella, L., Shipp, L., et al. (2014). Approaches to conserving natural enemy populations in greenhouse crops: current methods and future prospects. BioControl 59, 377-393. doi: 10.1007/s10526-014-9579-6

Messelink, G. J., Maanen, R., V., van Steenpaal, S. E. F., and Janssen, A. (2008). Biological control of thrips and whiteflies by a shared predator: two pests are better than one. Biol. Control 44, 372-379. doi: 10.1016/j.biocontrol.2007.10.017

Messelink, G. J., van Maanen, R., van Holstein-Saj, R., Sabelis, M. W., and Janssen, A. (2010). Pest species diversity enhances control of spider mites and whiteflies by a generalist phytoseiid predator. BioControl 55, 387-398. doi: 10.1007/s10526-009-9258-1 
Muñoz-Cárdenas, K., Ersin, F., Pijnakker, J., van Houten, Y., Hoogerbrugge, H., Leman, A., et al. (2017). Supplying high-quality alternative prey in the litter increases control of an above-ground plant pest by a generalist predator. Biol. Control 105, 19-26. doi: 10.1016/j.biocontrol.2016.11.004

Nomikou, M., Janssen, A., Schraag, R., and Sabelis, M. W. (2001). Phytoseiid predators as potential biological control agents for Bemisia tabaci. Exp. Appl. Acarol. 25, 271-291. doi: 10.1023/A:1017976725685

Nomikou, M., Janssen, A., Schraag, R., and Sabelis, M. W. (2002). Phytoseiid predators suppress populations of Bemisia tabaci on cucumber plants with alternative food. Exp. Appl. Acarol. 27, 57-68. doi: 10.1023/A:1021559 421344

Nomikou, M., Janssen, A., Schraag, R., and Sabelis, M. W. (2004). Vulnerability of Bemisia tabaci immatures to phytoseiid predators: consequences for oviposition and influence of alternative food. Entomol. Exp. Appl. 110, 95-102. doi: 10.1111/j.0013-8703.2004.00114.x

Nomikou, M., Sabelis, M. W., and Janssen, A. (2010). Pollen subsidies promote whitefly control through the numerical response of predatory mites. BioControl 55, 253-260. doi: 10.1007/s10526-0099233-x

Pappas, M. L., Xanthis, C., Samaras, K., Koveos, D. S., and Broufas, G. D. (2013). Potential of the predatory mite Phytoseius finitimus (Acari: Phytoseiidae) to feed and reproduce on greenhouse pests. Exp. Appl. Acarol. 61, 387-401. doi: 10.1007/s10493-013-9711-9

Pijnakker, J., Arijs, Y., de Souza, A., Cellier, M., and Wäckers, F. (2016). The use of Typha angustifolia (cattail) pollen to establish the predatory mites Amblyseius swirskii, Iphiseius degenerans, Euseius ovalis and Euseius gallicus in glasshouse crops. IOBC WPRS Bull. 120, 47-54. Available online at: https://www.iobcwprs.org/members/shop_en.cfm?mod_Shop_detail_produkte $=166$

Sabelis, M. W., and Janssen, A. (1994). "Evolution of life-history patterns in the phytoseiidae," in Mites: Ecological and Evolutionary Analyses of LifeHistory Patterns, ed M. A. Houck (Boston, MA: Springer US), 70-98. doi: 10.1007/978-1-4615-2389-5_4

Samaras, K. (2018). Biology and Ecology of the Predatory Mite Amblydromalus limonicus (Acari: Phytoseidae). PhD thesis, Democritus University of Thrace.

Samaras, K., Pappas, M. L., Fytas, E., and Broufas, G. D. (2015). Pollen suitability for the development and reproduction of Amblydromalus limonicus (Acari: Phytoseiidae). BioControl 60, 773-782. doi: 10.1007/s10526-0159680-5

Skirvin, D. J., Kravar-Garde, L., Reynolds, K., Jones, J., Mead, A., and Fenlon, J. (2007). Supplemental food affects thrips predation and movement of Orius laevigatus (Hemiptera: Anthocoridae) and Neoseiulus cucumeris (Acari: Phytoseiidae). Bull. Entomol. Res. 97, 309-315. doi: 10.1017/S0007485307005007

SPSS (2011). IBM SPSS Statistics Base 20. (c) copyright IBM Corporation.

Vacante, V. (2016). The Handbook of Mites of Economic Plants: Identification, Bio-ecology and Control. Boston, MA: CABI. van Baalen, M., Krivan, V., Van Rijn, P. C., and Sabelis, M. W. (2001). Alternative food, switching predators, and the persistence of predator-prey systems. Am. Natural. 157, 512-524. doi: 10.1086/319933

van Houten, Y. M., Rothe, J., and Bolckmans, K. J. F. (2008). The generalist predator Typhlodromalus limonicus (Acari: Phytoseiidae): a potential biological control agent of thrips and whiteflies. IOBC/wprs Bull. 32, 237-240. Available online at: https://www.iobc-wprs.org/members/shop_en. cfm?mod_Shop_detail_produkte $=85$

van Maanen, R., Messelink, G. J., Van Holstein-Saj, R., Sabelis, M. W., and Janssen, A. (2012). Prey temporarily escape from predation in the presence of a second prey species. Ecol. Entomol. 37, 529-535. doi: 10.1111/j.1365-2311.2012.01395.x

van Rijn, P. C. J., van Houten, Y. M., and Sabelis, M. W. (1999). Pollen improves thrips control with predatory mites. IOBC/wprs Bull. 22, 209-212.

van Rijn, P. C. J., van Houten, Y. M., and Sabelis, M. W. (2002). How plants benefit from providing food to predators even when it is also edible to herbivores. Ecology 83, 2664-2679. doi: 10.1890/0012-9658(2002)083[2664:HPBFPF]2.0. $\mathrm{CO} ; 2$

Vangansbeke, D., Nguyen, D. T., Audenaert, J., Verhoeven, R., Deforce, K., Gobin, B., et al. (2014a). Diet-dependent cannibalism in the omnivorous phytoseiid mite Amblydromalus limonicus. Biol. Control 74, 30-35. doi: 10.1016/j.biocontrol.2014.03.015

Vangansbeke, D., Nguyen, D. T., Audenaert, J., Verhoeven, R., Gobin, B., Tirry, L., et al. (2014b). Performance of the predatory mite Amblydromalus limonicus on factitious foods. BioControl 59, 67-77. doi: 10.1007/s10526-013-9 548-5

Vangansbeke, D., Nguyen, D. T., Audenaert, J., Verhoeven, R., Gobin, B., Tirry, L., et al. (2016). Supplemental food for Amblyseius swirskii in the control of thrips: feeding friend or foe? Pest Manag. Sci. 72, 466-473. doi: 10.100 2/ps.4000

Wäckers, F. L. (2005). "Suitability of (extra-)floral nectar, pollen, and honeydew as insect food sources," in Plant-Provided Food for Carnivorous Insects: A Protective Mutualism and its Applications, eds F. L. Wäckers, P. C. J van Rijn, and J. Bruin. (Cambridge: Cambridge University Press), 17-74. doi: 10.1017/CBO9780511542220.003

Conflict of Interest Statement: The authors declare that the research was conducted in the absence of any commercial or financial relationships that could be construed as a potential conflict of interest.

Copyright (C) 2019 Samaras, Pappas, Fytas and Broufas. This is an open-access article distributed under the terms of the Creative Commons Attribution License (CC BY). The use, distribution or reproduction in other forums is permitted, provided the original author(s) and the copyright owner(s) are credited and that the original publication in this journal is cited, in accordance with accepted academic practice. No use, distribution or reproduction is permitted which does not comply with these terms. 